\title{
Biological significance attenuates overshadowing, relative validity, and degraded contingency effects
}

\author{
PHILIPPE OBERLING \\ INSERM Unité 405, Strasbourg, France \\ ADAM S. BRISTOL \\ Yale University, New Haven, Connecticut \\ HELENA MATUTE \\ Universidad de Deusto, Bilbao, Spain
}

and

RALPH R. MILLER

State University of New York, Binghamton, New York

\begin{abstract}
Miller and Matute (1996) showed that blocking is attenuated when the blocked conditioned stimulus (CS) is "biologically significant" (i.e., when the CS has the potential to elicit vigorous responding of any kind). To the extent that blocking is representative of cue competition, this finding suggests that biological significance protects CSs against cue competition effects in general. In the present experiments, we tested this possibility by examining the influence of biological significance of CSs on other examples of cue competition, namely, overshadowing, the relative stimulus validity effect, and the degraded contingency effect in rats. In Experiment 1 , we found that intense auditory stimuli induced transient unconditioned lick suppression, thereby indicating that intense sounds were of high inherent biological significance. In Experiment 2A, we found that cues with high inherent biological significance were protected from overshadowing. In Experiment 2B, this finding was extended to cues with high acquired biological significance, which was obtained through prior pairings with a reinforcer of the valence opposite to that used in the overshadowing treatment. In Experiments 3 and 4 , we found that cues with high inherent biological significance attenuated the relative validity effect and the degraded contingency effect, respectively. These results lend support to the view that biological significance (inherent and acquired) protects stimuli from cue competition effects, a finding that is problematic for many contemporary theories of learning.
\end{abstract}

The concept of inherent biological significance has been well captured in the learning literature by the notion of an unconditioned stimulus (US). For example, Pavlov (1927) recognized that the stimulus he typically chose as a US (i.e., food) beckoned approach, salivation, ingestion, and so forth, whereas his conditioned stimuli (CSs) initially elicited only weak orienting responses. As a result, he concluded that USs had greater "biological strength" than

Support for this research was provided by National Institute of Mental Health Grant 33881, GIS Sciences de la Cognition Grant 97/C/51, Fondation Bettencourt-Schueller, Dirección General de Enseñanza Superior Grant PB95-0440, and Departamento de Educación, Universidades e Investigación del Gobierno Vasco Grant PI96-006. The authors thank James J. Esposito for his excellent technical assistance and Francisco Arcediano, Aaron P. Blaisdell, Daniel C. Burger, James C. Denniston, Martha Escobar, Hernan Savastano, and Russell Wishtart for their helpful comments on an earlier version of this manuscript. Correspondence should be addressed to R. R. Miller, Department of Psychology, State University of New York, Binghamton, NY 13902-6000 (e-mail: rmiller@binghamton.edu).

-Vincent M. LoLordo served as the editor for this article. did CSs, as could be observed in their potential to elicit stronger and more numerous responses. Hull's (1951) notion of stimulus intensity dynamism, which is the aspect of a CS's salience that he regarded as having a multiplicative relationship to other variables in eliciting responding, is another concept closely related to inherent biological significance. Thus, it is somewhat surprising to see that the notion of biological significance has received little theoretical scrutiny over the past 25 years. For example, the highly influential Rescorla-Wagner model of Pavlovian conditioning (Rescorla \& Wagner, 1972) addresses inherent biological significance of CSs only by attributing greater associability to cues of high inherent biological significance (see also Mackintosh, 1975, and Pearce \& Hall, 1980, according to whom the associability of a CS reflects both the inherent and acquired biological significance of the cue). As a result, the Rescorla-Wagner model does not accommodate Hull's and others' (e.g., Kamin, 1965; Kessen, 1953) finding that CS intensity (a quality that is clearly one component of biological significance) modulates the asymptotic magnitude of a conditioned response. 
The concept that biological significance is a stimulus attribute has recently received renewed attention from our research group (e.g., Denniston, Miller, \& Matute, 1996; Gunther, Miller, \& Matute, 1997; Miller \& Matute, 1996). ${ }^{.}$Clearly, the ideas of Pavlov (1927) and Hull (1951) are similar to our present concept of biological significance. A biologically significant stimulus can be defined as one that is relevant to the homeostatic regulation of an organism, homeostasis being used here in a broader sense than the one traditionally viewed by physiologists (e.g., Cannon, 1929; for recent developments, see Mrosovsky, 1990). Typically, stimuli that directly affect a homeostatic variable (e.g., food, water, sex, or stress, such as pain, heat, or cold) are biologically significant events in Cannon's sense, which we here call inherent biological significance. But stimuli that have been paired with such events, and hence convey information about events of inherent biological significance, may also be included in this category as part of a subcategory, which we here call acquired biological significance. Both types of stimuli are directly relevant to maintaining the stability of le milieu intérieur described by Claude Bernard (1856). Operationally, the degree to which a stimulus is biologically significant can be assessed in the laboratory by the type and magnitude of responding that it elicits. For example, when subjects withdraw their hands or paws from a hot plate, the reaction time for so doing is inversely proportional to the temperature of the plate. We say that this is a stimulus with high inherent biological significance because it elicits vigorous behavior (at least) when it is first encountered. In contrast, a stimulus (e.g., a soft tone or an abstract geometric shape presented on a computer) that does not elicit a vigorous response when initially presented but that does so as a consequence of being paired with a stimulus of inherent biological significance has what we call acquired biological significance.

Gunther et al. (1997) recently drew attention to the potential importance of biological significance in Pavlovian conditioning. They noted that differential processing of CSs and USs could be due, at least in principle, to differences in their biological significance (lower for CSs than for USs) or in their temporal ordering (CSs ordinarily occur prior to USs). Gunther et al.'s results indicated that it was the biological significance of the stimuli, rather than the temporal order of presentation, that was critical in determining whether a stimulus was processed as a CS or a US.

Along the same lines of research, Miller and Matute (1996; see also Denniston et al., 1996) were interested in the failure of previous research to demonstrate backward blocking (i.e., poor responding to $\mathrm{X}$ as a result of $\mathrm{A}-\mathrm{US}$ trials that follow $\mathrm{AX}$-US trials) with nonhuman subjects (see, e.g., Miller, Hallam, \& Grahame, 1990; Schweitzer \& Green, 1982). This failure contrasts with the successful demonstrations of backward blocking that have been obtained with humans in causal judgment studies (see, e.g.,
Chapman, 1991; Shanks, 1985). Miller and Matute noted that, in the human backward blocking studies, the outcomes were of low inherent biological significance (e.g., allergic reactions suffered by fictitious patients), whereas in the animal studies the outcomes (USs) were of high inherent biological significance. On the basis of this difference, they proposed that the past failures to observe backward blocking in nonhuman subjects occurred because the intended blocked stimulus $(\mathrm{X})$ had acquired biological significance during the first phase of training (i.e., $\mathrm{AX}$-US trials result in conditioned responding to $\mathrm{X}$ ), prior to the blocking treatment (i.e., A-US trials). A1ternatively stated, in the backward blocking procedure the AX-US pairings of Phase 1 produced conditioned responding to $X$ (which is difficult to eliminate once it is in place). In contrast, in the forward blocking procedure there was no point during which $\mathrm{X}$ had the capacity to elicit responding. Miller and Matute's data support the view that this difference was critical in determining whether backward blocking would be observed. Using a sensory preconditioning procedure to protect the to-beblocked stimulus $(\mathrm{X})$ from gaining biological significance during Phase 1, Miller and Matute successfully demonstrated backward blocking in nonhuman subjects. Additionally, Miller and Matute's Experiment 3 demonstrated that forward blocking also required the to-beblocked stimulus to be of low biological significance. To the degree that blocking is representative of associative cue competition effects in general, these findings suggest that biological significance may be an important factor in determining the outcome of other cue competition treatments. The present series of experiments was designed to address this question.

In addition to blocking (Kamin, 1968), at least three other Pavlovian conditioning phenomena seemingly are forms of associative competition between cues trained in compound. These phenomena are known as overshadowing (Pavlov, 1927), the relative stimulus validity effect (e.g., Wagner, Logan, Haberlandt, \& Price, 1968; Wasserman, 1974), and the degraded contingency effect (e.g., Rescorla, 1968). In a typical overshadowing procedure, the subjects are exposed to two CSs presented in compound (A and $\mathrm{X}$, with $\mathrm{A}$ being more salient than $\mathrm{X}$ ) followed by the US (i.e., AX-US). Overshadowing is said to be evident if subsequent responding to $X$ during testing is impaired relative to the performance of control subjects that were exposed to $\mathrm{X}$ alone followed by the US (i.e., X-US).

Competition between two CS-US associations is affected not only by the relative saliences of the CSs (as in overshadowing), but also by what Wagner et al. (1968) called the relative validities of the CSs. That is, a more valid cue (i.e., one which better predicts the occurrence of reinforcement) will attenuate responding to a less valid one. In a typical relative stimulus validity procedure, the subjects are exposed to two pairs of (equally 
salient) compounded CSs (i.e., AX and BX), which are randomly interspersed. For all subjects, CS X is followed by the US on $50 \%$ of the trials. However, for some subjects (Group Correlated), CS A always predicts the occurrence of the US, whereas CS B always predicts nonreinforcement (i.e., AX-US/BX-noUS). For other subjects (Group Uncorrelated), A and B do not predict the occurrence of the US any more reliably than does X (i.e., $\mathrm{AX}$ and $\mathrm{BX}$ are each reinforced on $50 \%$ of their presentations). In the absence of a more valid predictor of the US (Group Uncorrelated), X acquires substantial control over responding. However, in the presence of a more valid predictor (i.e., CS A in Group Correlated), X comes to elicit relatively little conditioned responding.

Finally, in a typical degraded contingency procedure (e.g., Rescorla, 1968), all subjects experience CS-US pairings, but some subjects receive additional unsignaled US presentations interspersed among the CS-US pairings. In this case, the added USs degrade the CS-US contingency, thereby greatly attenuating subsequent responding to the CS during testing relative to that of control subjects, which were not exposed to the added unsignaled USs. The degraded contingency effect is generally thought to arise from a context-US association that "blocks" the CS-US association (Ayres, Bombace, Shurleff, \& Vigorito, 1985; Randich \& Ross, 1984).

The present research demonstrates that overshadowing is attenuated by the use of CSs that have either high inherent (Experiment 2A) or high acquired (Experiment 2B) biological significance, and demonstrates that the relative stimulus validity effect (Experiment 3 ) and the degraded contingency effect (Experiment 4 ) are also attenuated by the use of CSs of high inherent biological significance. Results from Experiment 1 show that intense auditory cues have high inherent biological significance.

\section{EXPERIMENT 1 \\ Evidence That Intense Auditory Cues Have Inherent Biological Significance}

Experiment 1 was a preliminary, but necessary, study intended to assess whether the high-intensity auditory stimuli used in the subsequent experiments were of high inherent biological significance, as indicated by their potential to elicit unconditioned responding in our preparation. As stated previously, we view a stimulus as being of high biological significance if it elicits a strong unconditioned (or conditioned) response. Furthermore, because unconditioned responding is a potential confound in Experiments 2-4, we sought to determine whether responding to these intense stimuli would habituate with a modest number of exposures to the stimuli, so that we would know whether unconditioned responding would likely prove to be a confound in the subsequent experiments. Thus, we expected that a novel, intense auditory stimulus would elicit strong unconditioned suppression of drinking in our lick-suppression preparation, but that the suppression would quickly habituate toward baseline levels after a few stimulus presentations.

\section{Method}

\section{Subjects}

The subjects were 18 male and 18 female experimentally naive Sprague-Dawley descended rats obtained from our own breeding colony at SUNY-Binghamton. Body weights ranged from 212 to $296 \mathrm{~g}$ for males and from 195 to $256 \mathrm{~g}$ for females. The subjects were randomly assigned to one of three groups ( $\mathrm{M}, \mathrm{L}$, or Pre- $\mathrm{L}, n \mathrm{~S}=12)$, counterbalanced for sex. The animals were individually housed in standard hanging stainless steel wire-mesh cages in a vivarium maintained on a 16:8-h light:dark cycle (light on at $0600 \mathrm{~h}$ ), with experimental manipulations occurring near the middle portion of the light phase. The animals were allowed free access to Purina Laboratory Chow, whereas access to water was limited to $10 \mathrm{~min} /$ day following a progressive deprivation schedule imposed the week prior to the start of the study. From the time of weaning until the initiation of the study, all animals were handled three times a week for $30 \mathrm{sec}$.

\section{Apparatus}

Owing to availability, two types of enclosures were used. Enclosure $\mathrm{R}$ was a clear, Plexiglas, rectangular chamber measuring 31.75 $\times 8.25 \times 13.0 \mathrm{~cm}(\mathrm{I} \times \mathrm{w} \times \mathrm{h})$. The floor was constructed of 0.48 $\mathrm{cm}$-diameter rods, spaced $1.5 \mathrm{~cm}$ center to center, connected by NE2 neon bulbs which allowed the delivery of constant-current footshock by means of high-voltage ac circuit in series with a $1.0-\mathrm{M} \Omega$ resistor. Each of six copies of Enclosure $\mathrm{R}$ was housed in a separate light- and sound-attenuating environmental isolation chest. Enclosure $\mathrm{R}$ was dimly illuminated by a $2-\mathrm{W}$ (nominal at $120 \mathrm{~V}$ ac) bulb driven at $56 \mathrm{~V}$ ac. The bulb was mounted on an inside wall of the environmental chest approximately $30 \mathrm{~cm}$ from the center of the experimental chamber. Background noise, mostly from a ventilation fan, was $78 \mathrm{~dB}$ (all sound level readings were performed on the Cscale and based on standard pressure level).

Enclosure V was a $22.30-\mathrm{cm}-l o n g$ box in the shape of a vertical truncated V. The enclosure was $26.20 \mathrm{~cm}$ high, $21.00 \mathrm{~cm}$ wide at the top, and narrowed to $5.25 \mathrm{~cm}$ wide at the bottom. The ceiling was constructed of clear Plexiglas, the end walls were black Plexiglas, and the sloping sidewalls (which gave the chamber its V shape) were stainless steel. The floor consisted of two long parallel metal plates, each $2 \mathrm{~cm}$ wide, separated by a $1.25-\mathrm{cm}$ gap. A constantcurrent footshock could be delivered through the metal walls and floor of the chamber. Each of six copies of Enclosure $V$ was housed in a separate light- and sound-attenuating environmental isolation chest. Enclosure V was dimly illuminated by a $7.5-\mathrm{W}$ (nominal at $120 \mathrm{~V} \mathrm{ac}$ ) bulb driven at $56 \mathrm{~V}$ ac. This houselight was mounted on an inside wall of the environmental chest approximately $30 \mathrm{~cm}$ from the center of the experimental chamber. Light entered the experimental enclosure primarily by reflection from the roof of the environmental chest. The light intensity in Enclosure $V$ roughly matched that in Enclosure R, because the difference in the luminosity of the light bulbs compensated for the difference in the opaqueness of the walls of the two types of enclosures. The houselight was on throughout the experiment. Background noise, mostly from a ventilation fan, was $78 \mathrm{~dB}$.

Enclosures $R$ and V could each be equipped with a water-filled lick tube. When inserted, the lick tube extended about $1 \mathrm{~cm}$ into a cylindrical drinking recess that was set into one of the narrow Plexiglas walls of the chamber (axis perpendicular to wall). Each drinking recess was left-right centered on the chamber wall, with its bottom $1.75 \mathrm{~cm}$ above the floor of the apparatus. The recess was $4.5 \mathrm{~cm}$ in diameter and $5.0 \mathrm{~cm}$ deep. An infrared photobeam was projected across the recess approximately $1 \mathrm{~cm}$ in front of the lick tube. In order to drink from the lick tube, the subject had to insert its head 
into the recess, thereby breaking the photobeam. Thus, the time during which the subjects were licking could be recorded.

Each enclosure was equipped with three speakers mounted on the interior walls of the environmental chest. Each speaker could deliver a different auditory stimulus, specifically a white noise $(\mathrm{N})$, a $10 / \mathrm{sec}$ click train (C), or a complex $3000-3200 \mathrm{~Hz}$ tone (T).

\section{Procedure}

Acclimation. On Day 1, the subjects were acclimated to their respective enclosure, $\mathrm{R}$ or $\mathrm{V}$, counterbalanced within groups, during a 60 -min session. Lick tubes were present.

Training. Following acclimation, the lick tubes were removed from all enclosures. On Days 2 and 3, the subjects in Group Preexposureto-the-Loud-Sound (Pre-L) received four daily nonreinforced exposures to the intense white noise presented $26 \mathrm{~dB}$ above the ambient background noise at $10,20,37$, and $50 \mathrm{~min}$ into the daily 60 -min sessions. All stimulus presentations were $10 \mathrm{sec}$ in duration. The subjects in Groups Moderate-Sound (M) and Loud-Sound (L) experienced equivalent context exposure with no nominal stimulus presentations.

Reacclimation. On Day 4, the lick tubes were returned to the apparatus and all subjects were reacclimated to their enclosure during a 60-min session.

Testing. On Day 5, during a 16-min session each subject was tested individually for suppression in response to the white noise, which was presented at $26 \mathrm{~dB}$ above the ambient background noise for Groups Pre-L and L, and at $6 \mathrm{~dB}$ above background for Group $\mathrm{M}$. The white noise was presented to the subject on the test trial upon completion of its initial 5 cumulative seconds of drinking in the absence of any nominal stimulus. Thus, each subject was drinking at the onset of the white noise, and the time required to complete an additional 5 cumulative seconds of drinking in the presence of the noise was measured with a 900 -sec ceiling being imposed on each time. Testing of the animals was staggered (counterbalanced between groups), and the animals were transported from the colony so that those not yet tested were unable to hear cues being presented to the other animals. Suppression times were transformed to $\log$ (base 10) times to better approximate normal distributions of scores within groups, which is assumed in the use of parametric statistical tests. An alpha level of .05 was adopted for all tests of statistical significance.

Owing to illness, two animals (one from Group $L$ and one from Group Pre-L) were excluded from the study prior to testing.

\section{Results and Discussion}

Figure 1 depicts the results of Experiment 1. A high level of unconditioned suppression to the loud noise was observed, but only in Group L. Groups $M$ and Pre- $L$ displayed a mean level of unconditioned suppression, which was close to the minimum possible $(\log 5 \mathrm{sec}=0.70)$.

A one-way analysis of variance (ANOVA) with group as the factor found that there were no differences among groups in baseline drinking behavior on the test day (i.e., in time to complete the first 5 cumulative seconds of drinking, which was prior to the presentation of the stimulus) $[F(2,31)<1]$.

A similar ANOVA conducted on time to complete 5 cumulative seconds of drinking in the presence of the white noise revealed a difference between groups $[F(2,31)=12.62]$. Planned comparisons using the error term from the ANOVA found differences between Groups $M$ and $L[F(1,31)=19.59]$ and Groups $L$ and Pre-L $[F(1,31)=18.53]$.

These results indicate that there was greater lick suppression to the novel, intense auditory stimulus than to

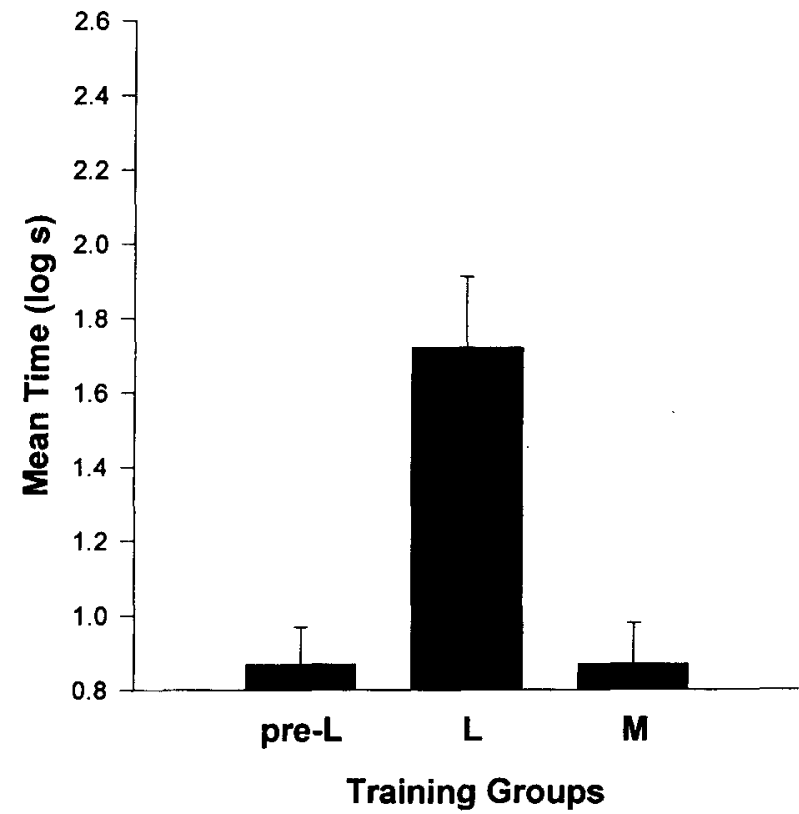

Figure 1. Experiment 1. Mean latencies to complete 5 cumulative seconds of drinking in the presence of the white noise stimulus, which was of high intensity for Groups Pre-L and $L$, and moderate intensity for Group M. Group Pre-L was given eight exposures to its test $\mathrm{CS}$, whereas the two other groups received only comparable exposure to the context. Error bars indicate the standard error of the mean.

the equally novel, but less intense, auditory stimulus. Therefore, the 26-dB (above background) auditory stimulus appears to have been of greater biological significance than was the otherwise equivalent $6-\mathrm{dB}$ (above background) auditory stimulus. Moreover, this strong unconditioned response was greatly reduced by eight nonreinforced trials, which demonstrates rapid habituation of this response. In Experiments 2A, 3, and 4, we demonstrated that despite habituation of unconditioned responding, intense CSs retain a quality, which we call biological significance, that protects them from cue competition (see Blaisdell, Denniston, Savastano, \& Miller, 2000, for a demonstration of acquired biological significance's surviving extinction of conditioned responding). In the General Discussion, we discuss the perseverance of biological significance beyond the time that the stimulus had the potential to elicit responding.

\section{EXPERIMENT 2A \\ Overshadowing Treatment With Cues of Inherent Biological Significance}

In Experiment 1, we demonstrated that a loud, but not a moderate, noise elicits unconditioned suppression of drinking in thirsty rats, a result that is congruent with our previous findings that an intense auditory cue is a biologically significant event for rats (see Denniston et al., 1996; Gunther et al., 1997; Miller \& Matute, 1996). In Experiment 1 , we also demonstrated that this unconditioned 
response quickly habituates with repeated exposure. This latter result allowed us to study the impact of biologically significant cues on conditioning phenomena without any major confound due to unconditioned responding.

Miller and Matute (1996, Experiment 3) demonstrated that a stimulus with inherent biological significance was protected against forward blocking. The purpose of the present series of experiments was to determine whether their finding could be extended to other forms of Pavlovian cue competition. In particular, Experiment $2 \mathrm{~A}$ was designed to determine whether this protection from cue competition afforded by the target cue's being biologically significant could also be observed in an overshadowing paradigm. Notably, Mackintosh (1976) reported that when intense CSs were used, overshadowing was greatly attenuated. Although suggestive, Mackintosh's experiment did not control for unconditioned responding to the intense overshadowed CS that he used. The present study included such a control. In Condition Loud (L), the target (i.e., overshadowed) CS was of high biological significance, whereas in Condition Moderate (M), it was of low biological significance. To avoid perceptual masking (as distinct from associative overshadowing) of the intended overshadowing cue by the overshadowed cue, the intensity of the overshadowing cue was correspondingly increased as the intensity of the overshadowed cue was manipulated. Specifically, we maintained for all subjects a constant ratio of intensities (corresponding to a difference of $4 \mathrm{~dB}$ ) between the overshadowing and overshadowed CSs. This should have resulted in roughly similar differences in salience between the overshadowing and overshadowed CSs in the moderate- and highintensity conditions because salience is generally assumed to be roughly proportional to $\log$ intensity.

\section{Method \\ Subjects and Apparatus \\ The subjects were 30 male and 30 female naive Sprague Dawley descended rats obtained from our own breeding colony. Body weights ranged from 265 to $345 \mathrm{~g}$ for males and from 195 to $260 \mathrm{~g}$ for fe- males. The subjects were randomly assigned to one of five groups counterbalanced for sex (AX-M, X-M, AX-L, X-L, and Cont-L, $n \mathrm{~s}=12$ ). Animal care and the apparatus were the same as in Exper- iment 1 . Enclosures $\mathrm{R}$ and $\mathrm{V}$ were counterbalanced within groups.}

\section{Procedure}

The parameters and procedural details were the same as in Experiment 1 , except where otherwise stated. The overshadowing stimulus was the click train, presented as a stimulus of either low biological significance ( $10 \mathrm{~dB}$ above background) or high biological significance ( $30 \mathrm{~dB}$ above background). The overshadowed stimulus was the white noise, presented as a stimulus of either low biological significance ( $6 \mathrm{~dB}$ above background) or high biological significance ( $26 \mathrm{~dB}$ above background). For the overshadowing groups, the difference in intensity between the overshadowing and overshadowed CSs was always $4 \mathrm{~dB}$. Consequently, because the decibel scale for sound level is a log function of physical intensity, the ratios of the physical intensities of the overshadowed stimulus to the overshadowing stimulus was constant (for more detail, see Stevens, 1959). Both stimuli were $10 \mathrm{sec}$ in duration. The US was a 0.5 -sec, $0.7-\mathrm{mA}$ footshock. On all reinforced trials, the US was presented immediately upon termination of the CS.
Acclimation. Acclimation to the experimental enclosure was conducted on Days 1 and 2 during daily 60 -min sessions. During these sessions, no nominal stimuli were presented, and free access to water-filled lick tubes was provided.

Conditioning. Conditioning was conducted on Days 3 and 4 with the lick tubes removed. During each daily 60 -min session, Groups AX-M and AX-L experienced four AX-US trials (with A representing the overshadowing clicks and $X$ representing the overshadowed white noise), whereas the Groups $\mathrm{X}-\mathrm{M}$ and $\mathrm{X}-\mathrm{L}$ experienced four $\mathrm{X}$-US trials and four A-alone presentations pseudorandomly interspersed). Group Cont-L experienced daily four X-alone presentations and four A-US trials. Cont denotes a control condition for assessment of unconditioned responding, $\mathrm{AX}$ and $\mathrm{X}$ refer to the stimuli reinforced during training, $L$ denotes the use of loud stimuli (high biological significance), and $M$ denotes the use of moderate intensity stimuli (low biological significance). The average intertrial interval (ITI) was $12 \mathrm{~min}$ (range $=7-17 \mathrm{~min}$ ).

Reacclimation. On Days 5 and 6, the water-filled lick tubes were reinserted and daily $60-\mathrm{min}$ reacclimation sessions were conducted. These sessions were intended to reestablish a stable rate of drinking for all subjects.

Testing. On Day 7, all subjects were tested for suppression in response to the overshadowed stimulus (X) using the same procedure as in Experiment 1.

Two subjects were discarded before testing because of an equipment failure during training (one in Group $\mathrm{X}-\mathrm{M}$ and the other in Group X-L).

\section{Results and Discussion}

Figure 2 depicts the results of Experiment 2A. Less conditioned suppression to $X$ was observed in Group $\mathrm{AX}-\mathrm{M}$ than in Group $\mathrm{X}-\mathrm{M}$, whereas both Group $\mathrm{AX}-\mathrm{L}$

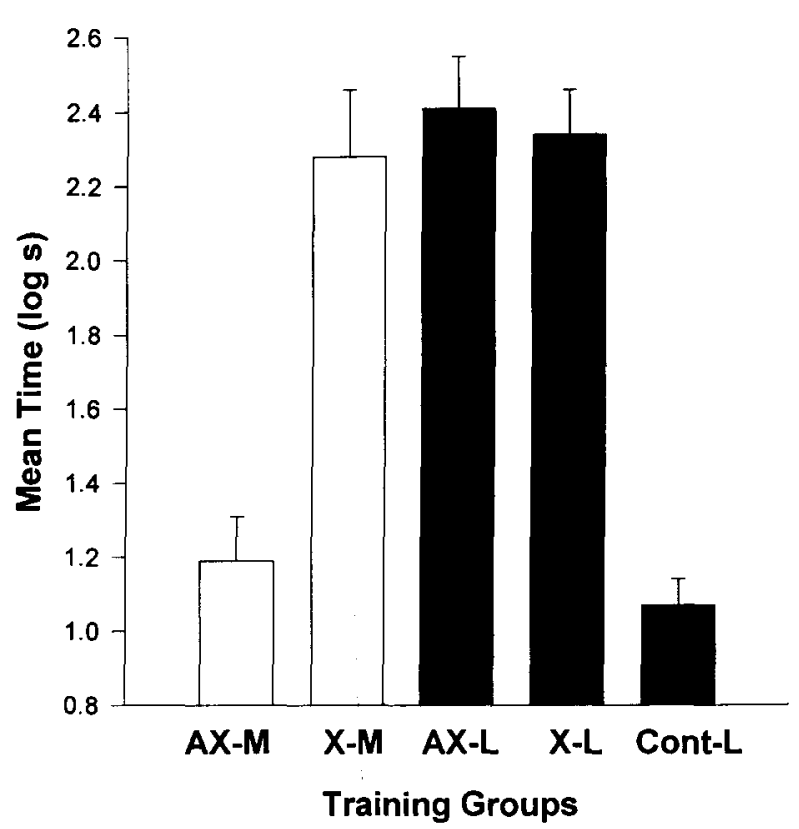

Figure 2. Experiment 2A. Mean latencies to complete 5 cumulative seconds of drinking in the presence of Stimulus $X$. Groups $A X-M$ and $X-M$ were trained and tested with stimuli of moderate intensity, whereas Groups $A X-L, X-L$, and Cont-L were trained and tested with stimuli of high intensity. To encourage overshadowing of CS X by CS A, within each stimulus intensity condition, $A$ was $4 \mathrm{~dB}(\mathrm{C})$ louder than $X$. Error bars indicate the standard error of the mean. 
and Group X-L displayed similar and high levels of suppression to X. Group Cont-L exhibited a low level of suppression to $X$, which indicates that the high level of suppression observed in Group $\mathrm{AX}-\mathrm{L}$ was not an unconditioned reaction to an intense noise. Thus, this experiment demonstrated that a CS with high inherent biological significance could not be overshadowed to the extent that a CS of lower biological significance could be. The following analyses support this conclusion.

A one-way ANOVA with group as the factor found no difference in the time to complete the first 5 cumulative seconds of licking on the test day (i.e., prior to the presentation of any test stimulus) $[F(4,53)=2.14]$, which is indicative of similar baseline behavior across groups.

A similar ANOVA conducted on time to drink for 5 cumulative seconds in the presence of $X$ revealed differences between groups $[F(4,53)=26.30]$. A second statistical analysis was then performed, excluding Group Cont- $\mathrm{L}$ in order to take advantage of the factorial arrangement of the four remaining groups. This $2 \times 2$ ANOVA, with intensity (loud vs. moderate) and treatment (AX vs. $\mathrm{X})$ as factors, revealed main effects of intensity $[F(1,42)$ $=19.70]$ and treatment $[F(1,42)=12.68]$ and an intensity $\times$ treatment interaction $[F(1,42)=16.46]$. Planned comparisons using the error term from the four-group ANOVA revealed that conditioned suppression to $X$ was lower in Group AX-M than in its control (Group X-M) $[F(1,42)=29.01]$. No significant difference was detected between Group AX-L and its control (Group X-L) $[F(1,42)=0.12]$.

An alternative view of the results of this experiment is that, despite our matching the ratio of intensities at the moderate and high intensities, there might have been a smaller difference in salience between the overshadowing and overshadowed CSs in the high-intensity condition than in the moderate-intensity condition; such a reduction in the difference in salience between CSs A and $X$ would be expected to reduce overshadowing according to all contemporary models of learning. Since there was no independent measure of salience, we cannot discount this possibility. However, available psychophysical data from humans (Stevens, 1959) suggest that maintaining the ratio of sound-level intensities between $A$ and $X$ should have roughly maintained the difference in saliences. Moreover, an account of Experiment 2A predicated on a reduced difference in saliences would not be able to explain the findings of Experiments 3 and 4, whereas an account based on biological significance applies equally well to Experiments 2, 3, and 4.

The results of the present experiment suggest that overshadowing is attenuated when CSs of high inherent biological significance are used. Notably, this attenuation of overshadowing does not result from a ceiling effect because very few animals suppressed for the full 900 -sec limit $(\log 900 \mathrm{sec}=2.95)$. The absence of a ceiling effect was also evident in all of the remaining studies in this series. Moreover, the low level of suppression to $\mathrm{X}$ that was displayed by Group Cont-L suggests that the abolition of overshadowing observed when using intense CSs cannot be attributed to unconditioned suppression to an intense noise. However, since this latter group had experienced $\mathrm{X}$-alone trials interspersed with A-US trials during training, the low level of responding that was observed could have reflected differential conditioned inhibition to the intense CS X rather than habituation of unconditioned suppression. The present data do not speak to this issue, but in Experiment 1, we observed low suppression in the animals that received the same number of nonreinforced exposures to X (Group Pre-L) as the present control group, which suggests that the low suppression observed here was more likely the result of habituation than of differential inhibition.

The high level of suppression observed in both Groups $\mathrm{AX}-\mathrm{L}$ and $\mathrm{X}-\mathrm{L}$ in Experiment $2 \mathrm{~A}$ might be viewed as a consequence of sensitization to the loud white noise that served as $\mathrm{X}$ rather than as a consequence of conditioning to the white noise. In fact, in Experiment 1, we found that this loud white noise unconditionally disrupted drinking when it was first encountered, but that this unconditioned response quickly habituated. However, one could argue that the close proximity of the footshock US to the white noise in Experiment 2A prevented habituation of the unconditioned response to the loud auditory cue, so that habituation could not counteract any sensitization that might have occurred over presentations of the loud auditory cues as a result of exposure to the auditory cue or the footshock. The lick suppression data presented here do not allow us to reject this possibility. However, through visual observation of the subjects (by the experimenter through a peephole in the environmental chest) in this and in the subsequent experiments, it was found that, when loud auditory stimuli were first presented, the rats tried to flee from the source of the sound. In contrast, with repeated exposures during the conditioning trials, the subjects exhibiting high suppression scores at test froze rather than fled, a behavioral response clearly different from the unconditioned response to loud auditory stimuli in this situation.

\section{EXPERIMENT 2B Overshadowing Treatment With Cues of Acquired Biological Significance}

In Experiment 2A, we demonstrated that a stimulus with inherent biological significance was protected from overshadowing. Experiment $2 \mathrm{~B}$ was designed to determine the extent to which the same might be true for a stimulus that had acquired biological significance through prior association. In other words, in Experiment 2B, we sought to determine whether merely high-intensity cues provided protection against overshadowing, or whether this protection arose from what we have more broadly conceptualized as biological significance. If only CSs of high intensity are protected against cue competition, the concept of biological significance as used here would be superfluous and the protection from overshadowing observed 
in Experiment $2 \mathrm{~A}$ could be attributed to preassociative perceptual processes. Thus, the current experiment was designed to determine the extent to which an overshadowing deficit can be reduced when the to-be-overshadowed stimulus (selected to have perceptual properties that ordinarily allow overshadowing) has previously been trained as a CS with a US that is distinctly different from that used in the overshadowing task. This goal was achieved by associating a to-be-overshadowed stimulus of low inherent biological significance (i.e., moderate intensity) with an appetitive reinforcer (saccharin) prior to the administration of overshadowing treatment with a different reinforcer (footshock). Importantly, these two reinforcers were selected because they elicit incompatible responses. Therefore, stronger suppression, indicative of the target $\mathrm{CS}-$ footshock association, as a result of the prior CSsaccharin pairings could not be attributed to response summation.

\section{Method}

\section{Subjects}

The subjects were 24 male and 24 female Sprague-Dawley descended rats obtained from our own breeding colony. Body weights ranged from 325 to $485 \mathrm{~g}$ for males and from 225 to $300 \mathrm{~g}$ for females. The subjects were randomly assigned to one of four groups (AX-Exp, X-Exp, AX-Cont, and X-Cont, $n s=12$ ), counterbalanced for sex. Animal care and maintenance were the same as in Experiment 1 .

\section{Apparatus}

Twelve identical operant Plexiglas chambers, each measuring 30 $\times 25 \times 32 \mathrm{~cm}(1 \times \mathrm{w} \times \mathrm{h})$, were used. The floor of each chamber was constructed of $0.5-\mathrm{cm}$-diameter rods, spaced $2 \mathrm{~cm}$ center to center, connected by NE-2 neon bulbs that allowed a $1.0-\mathrm{mA}$ constant-current footshock to be delivered by means of a high-voltage ac circuit in series with a $1.0-\mathrm{M} \Omega$ resistor. Each chamber was housed in an environmental isolation chest that was dimly illuminated by a No. 1820 incandescent houselight mounted on the ceiling of the experimental chamber. Each chamber included a cylindrical niche, $4.5 \mathrm{~cm}$ in diameter and left-right centered with its axis $4 \mathrm{~cm}$ above the grid floor, in which liquids could be delivered. Two means of delivering liquid to the animal were used at different times during the study. One was a water-filled lick tube (opening $=0.3 \mathrm{~cm}$ in diameter) that extended about $1 \mathrm{~cm}$ from the rear of a $5.5 \times 5.5$ $\times 4 \mathrm{~cm}(1 \times \mathrm{h} \times \mathrm{d})$ cylindrical recess at a height of $1 \mathrm{~cm}$ above the floor, which allowed for ad lib drinking, and the other was a liquid dispenser system (Lafayette Instrument Company No. 80201), which included a metallic spout located on the roof of the recess $5.5 \mathrm{~cm}$ from the floor and $2.25 \mathrm{~cm}$ forward of the rear of the recess. This dispensing system was capable of delivering variable amounts of liquid at programmed intervals into a small cup on the floor of the recess. In order to drink from the tubes or cup, the subjects had to insert their heads sufficiently far into the recess to break a horizontal infrared photobeam that passed across $1.5 \mathrm{~cm}$ into the recess. Thus, the amount of time the photobeam was disrupted could be monitored and served as our dependent measure of drinking for both liquid delivery systems.

A $75-\mathrm{W}$ (nominal at $120 \mathrm{~V} \mathrm{ac}$ ) incandescent bulb (driven at $100 \mathrm{vac}$ ) mounted on the back wall of each environmental chest could deliver a flashing light $(0.25 \mathrm{sec}$ on $/ 0.25 \mathrm{sec}$ off $)$. The houselight was off whenever the flashing light stimulus was cycling. A speaker mounted on the interior back side of each environmental chest could deliver a high-frequency complex tone $(3000$ and $3200 \mathrm{~Hz}$ ) $6 \mathrm{~dB}$ above background, and a second speaker mounted on the side- wall was used to deliver a white noise $(\mathrm{X})$ stimulus $6 \mathrm{~dB}$ above background. A third 45-W speaker mounted on the outside ceiling of the experimental chamber, directed toward the subject, was used to deliver a click stimulus $(6 / \mathrm{sec}) 6 \mathrm{~dB}$ above background. Ventilation fans in each enclosure provided a constant 76-dB background noise. All CSs were $10 \mathrm{sec}$ in duration. The footshock US was $1.0 \mathrm{~mA}, 0.5 \mathrm{sec}$ in duration and was presented immediately at the termination of the CSs on all reinforced trials.

Two distinct contexts were used in this study, one for the training, during which the to-be-overshadowed CS acquired biological significance (Context $A$ ), and a second one for overshadowing treatment and testing (Context $\mathrm{B}$ ). This context shift between training regimes was intended to reduce the magnitude of counterconditioning that might arise from our pairing the target CS with two reinforcers that elicited incompatible unconditioned responses (for a discussion of counterconditioning, see Pearce \& Dickinson, 1975; for a discussion of the contextual modulation of counterconditioning, see Bouton, 1993), thus allowing for a more sensitive test of a possible attenuation of overshadowing. Context A consisted of the operant chambers with all the aforementioned features plus Plexiglas floor plates that covered the grid floors and the addition of a distinctive odor. The odor cue was produced by placing one drop of methyl salicylate onto a small wood block located inside each environmental chest. Context $B$ was the aforementioned operant chamber with the accompanying features, but without the Plexiglas floor plates and odor cue.

\section{Procedure}

Acclimation. All subjects were acclimated to Contexts A and B on Days 1 and 2, respectively. The daily context exposure sessions were $60 \mathrm{~min}$ in duration. No nominal stimulus presentations occurred during these sessions, and the lick tubes were removed.

Phase 1: Treatment to make target CS (X) biologically significant. On Days 2-7, all subjects were placed in Context A for 60 -min daily sessions. The subjects in Groups AX-Exp and X-Exp received eight daily exposures to the to-be-overshadowed Stimulus X (tone or white noise, counterbalanced within groups) followed immediately by the saccharin solution $(0.05 \mathrm{ml}$ at $0.04 \mathrm{M})$, pseudorandomly interspersed with eight nonreinforced presentations of a nontarget Stimulus $Z$ (clicks). The subjects in Groups $\mathrm{AX}$ - Cont and $X$-Cont received eight daily exposures of Stimulus $Y$ (white noise or tone, counterbalanced within groups) followed immediately by the saccharin solution pseudorandomly interspersed with eight nonreinforced presentations of $Z$. Stimulus $Y$ was paired with saccharin for these groups in order to equate them with the Exp condition with respect to experience with saccharin exclusive of $X$-saccharin pairings. The nonreinforced $Z$ trials were interspersed with the $\mathrm{X}$-saccharin (or Y-saccharin) trials to constitute a discrimination procedure intended to facilitate acquisition of an $\mathrm{X}$-saccharin (or $\mathrm{Y}$-saccharin) association. The $\mathrm{X}$ or $\mathrm{Y}$ presentations, but not the $\mathrm{Z}$ presentations, were followed by presentation of the saccharin solution, because saccharin has been shown to be an effective reinforcer in classical conditioning paradigms (e.g., Garcia, 1989). These $X$ (or $Y$ ) and $Z$ trials occurred pseudorandomly within the session with a mean ITI of $225 \mathrm{sec}$ (range $=150-300 \mathrm{sec}$ ). In order to determine whether the animals had learned the $X$-saccharin (or $\mathrm{Y}$-saccharin) association, duration of nosepoking into the reinforcement recess was measured during each cue presentation. A performance index $(\mathrm{R})$ was then calculated $[\mathrm{R}=(\mathrm{X}[$ or $\mathrm{Y}]-\mathrm{Z})$ / $(\mathrm{X}[$ or $\mathrm{Y}]+\mathrm{Z})]$, with $\mathrm{X}, \mathrm{Y}$, and $\mathrm{Z}$ being the sum of the nosepoke durations recorded during the presentation of the appropriate cue for any given day. A quotient of 0 was indicative of a total absence of discrimination between $\mathrm{X}$ (or $\mathrm{Y}$ ) and $\mathrm{Z}$ and a quotient of 1 was indicative of a perfect discrimination.

Phase 2: Overshadowing treatment. Training on Days 8 and 9 occurred in Context B during daily 60-min sessions in which Groups AX-Exp and AX-Cont received three daily compound ex- 
posures of Stimulus A (flashing light) and Stimulus X followed immediately by the footshock US. Groups X-Exp and X-Cont received three daily X-US trials. These trials occurred at 15,34 , and 50 min into the session. In addition, Groups X-Exp and X-Cont received three daily nonreinforced $A$ exposures at 18,39 , and 53 min into the session to equate exposure to Stimulus A across groups. Water was not available during the training sessions.

Reacclimation. On Days $10-12$, the subjects were placed in Context B for 60-min sessions with the lick tubes in place in order to establish baseline levels of licking behavior. No nominal stimulus was presented.

Testing. On Day 13, all the subjects were tested for lick suppression elicited by CS $\mathrm{X}$ in Context $\mathrm{B}$. The test was conducted as in Experiment $2 \mathrm{~A}$.

Six subjects ( 1 from Group AX-Exp, 2 from Group X-Exp, 1 from Group $\mathrm{AX}$-Cont, and 2 from Group $\mathrm{X}$-Cont) were excluded from the study prior to testing due to equipment failure or experimenter error.

\section{Results and Discussion}

On the last day of Phase 1 training, all groups exhibited greater nosepoke responding when the stimulus was paired with saccharin delivery than when paired with Stimulus $Z$, indicating a good discrimination between the different stimuli presented during this phase of training, $\mathrm{R}( \pm S E M)=0.76( \pm 0.10), 0.55( \pm 0.21), 0.65( \pm 0.10)$, and $0.64( \pm 0.16)$ for Groups AX-Exp, X-Exp, AXCont, and $\mathrm{X}$-Cont, respectively. Each of these means differed from 0 (all $p s<.05$ ). Thus, with the current defi-

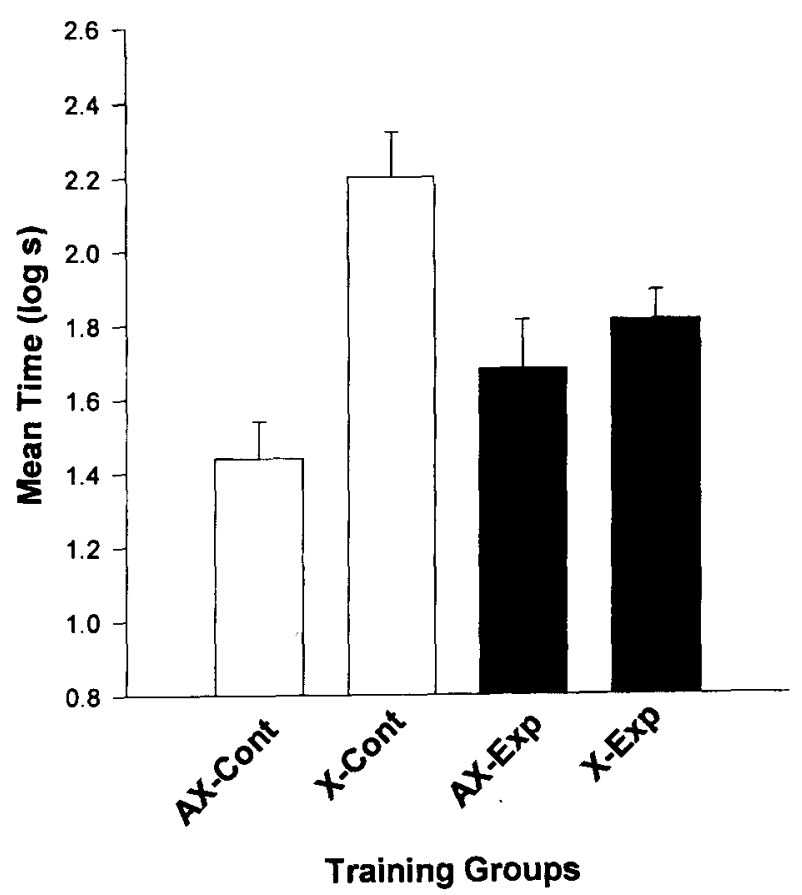

Figure 3. Experiment 2B. Mean latencies to complete 5 cumulative seconds of drinking in the presence of Stimulus $X$. During Phase 1 training, $X$ was associated with saccharin for Groups AX-Exp and $X$-Exp. To encourage overshadowing of CS $X$ by CS A, A was $4 \mathrm{~dB}(C)$ louder than $X$. Error bars indicate the standard error of the mean. nition of biological significance, Stimulus $\mathrm{X}$ (or Y) became biologically significant for each group during Phase 1 .

Figure 3 depicts the test day results for the overshadowed stimulus $(X)$. Less conditioned suppression to $X$ was observed in Group AX-Cont than in Group X-Cont, whereas Groups AX-Exp and X-Exp displayed a similar, intermediate level of suppression to $X$. Thus, Experiment 2B demonstrated that a CS that has acquired biological significance through prior association with a reinforcer could not be overshadowed to the same degree that a neutral CS could be. The following analyses support these conclusions.

A $2 \times 2$ ANOVA with Phase 1 treatment $(\mathrm{X}$-saccharin vs. $Y$-saccharin) and Phase 2 treatment (AX vs. $X$ ) as factors found no difference in time to complete 5 cumulative sec of licking prior to CS presentation on the test day [all $F_{\mathrm{S}}(1,38)<1.10$ ], which is indicative of similar baseline behavior across groups.

A $2 \times 2$ ANOVA for suppression in the presence of $X$ found no main effect of Phase 1 treatment $[F(1,38)=0.44]$, but did reveal an effect of Phase 2 treatment $[F(1,38)=$ 16.32] and a Phase $1 \times$ Phase 2 interaction $[F(1,38)=$ 7.98]. Planned comparisons revealed that conditioned suppression to $\mathrm{X}$ was lower in Group $\mathrm{AX}$-Cont than in Group X-Cont $[F(1,38)=23.57]$ but similar for Group $\mathrm{AX}$-Exp and Group X-Exp $[F(1,38)=0.74]$, respectively. It is noteworthy that Groups AX-Exp and X-Exp expressed a tendency toward an intermediate level of suppression in the presence of $X$, compared with Groups AX-Cont and X-Cont, respectively (see Figure 3). We shifted contexts between Phases 1 and 2 to reduce the likelihood that approach behavior conditioned with saccharin would reduce suppression of drinking conditioned with footshock. However, it is likely that the intermediate level of suppression observed in Groups AX-Exp and $X-$ Exp was a result of this ploy not being fully effective. In other words, the initial pairing of $X$ with saccharin could have weakened the acquisition (and/or the expression) of the association between $\mathrm{X}$ and the footshock, thereby producing a downward shift in suppression in the Exp condition. Importantly, although counterconditioning of $\mathrm{X}$ can account for suppression by Group $X$-Exp being lower than Group X-Cont, it cannot account for the Phase $1 \times$ Phase 2 interaction, which best documents that acquired biological significance of $X$ attenuated overshadowing. The possibility that the lack of overshadowing in Group AX-Exp was due to a floor effect (i.e., suppression by Group $\mathrm{X}$-Exp being too low to see any reduction) can be discounted by comparison with Group M of Experiment 1 (see Figure 1), which was similarly treated, but without footshock reinforcement. At test, there clearly was considerable associative-based suppression to X in Group X-Exp that in principle could have been reduced by overshadowing down to at least the level of Group M of Experiment 1.

In Experiment 2, it was shown that stimuli that had either inherent (Experiment $2 \mathrm{~A}$ ) or acquired (Experiment $2 B$ ) biological significance were protected from 
overshadowing. The fact that we could obtain a protective effect in Experiment $2 \mathrm{~B}$ with biologically significant cues of moderate intensity similar to the protective effect observed in Experiment 2A, which used high intensity cues, suggests that the protective effect does not rely purely on differential perceptual processing of intense CSs. Rather, it suggests that representations of cues with high biological significance, whether inherent or acquired, are processed differently than representations of cues with low biological significance.

\section{EXPERIMENT 3 \\ Relative Validity Treatment With Cues of Inherent Biological Significance}

In Experiments 2A and 2B, we demonstrated that overshadowing was attenuated when cues with biological significance (inherent or acquired, respectively) were used. Experiment 3 was designed to determine whether biological significance would also affect another form of cue competition, namely, the relative stimulus validity effect (Wagner et al., 1968; Wasserman, 1974). The relative validity effect refers to the observation that the presence, during training of a target cue $(\mathrm{X})$, of another cue (A) that is a better predictor of the presence of the outcome (US) than is $\mathrm{X}$ will reduce behavioral control by $X$, relative to otherwise equivalent conditions in which all cues are of equal predictive validity. If biological significance similarly influences all forms of cue competition, we would expect to observe a disruption of the relative stimulus validity effect when the target cue $(\mathrm{X})$ has high biological significance. Experiment 3 was conducted using CSs with inherent biological significance-in this case, auditory CSs of high intensity.

\begin{abstract}
Method

\section{Subjects and Apparatus}

The subjects were 30 male and 30 female Sprague-Dawley descended rats obtained from our own breeding colony. Body weights ranged from 290 to $470 \mathrm{~g}$ for males and from 240 to $330 \mathrm{~g}$ for females. The subjects were randomly assigned to one of five groups (Corr-L, Corr-M, Uncorr-L, Uncorr-M, and Cont-L; $n \mathrm{~s}=12$ ), counterbalanced for sex. Corr and Uncorr indicate the conditions in which A and B were perfectly correlated and poorly correlated, respectively, with the presence or absence of the US; Cont indicates a group to control for unconditioned responding to the loud CS. L and $\mathrm{M}$ indicate the conditions in which the cues $(\mathrm{A}, \mathrm{B}$, and $\mathrm{X})$ were loud (i.e., of high biological significance) and moderate (i.e., of low biological significance), respectively. Animal care and maintenance, as well as the apparatus, were the same as in Experiment 1. Enclosures $\mathrm{R}$ and $\mathrm{V}$ were counterbalanced within groups.
\end{abstract}

\section{Procedure}

The parameters and procedural details were the same as in Experiment $2 \mathrm{~A}$, except where otherwise stated. Stimuli A and B were the white noise and the tone, counterbalanced within groups; Stimulus $X$ was the $10 / \mathrm{sec}$ click train. All stimuli were presented at $8 \mathrm{~dB}$ above background to Groups Corr-M and Uncorr-M (i.e., moderate intensity), and at $30 \mathrm{~dB}$ above background to Groups Corr-L,
Uncorr-L, and Cont $-\mathrm{L}$ (i.e., loud) above the ambient background noise. On all reinforced trials, the US ( $1.0-\mathrm{mA}$ footshock for $0.5 \mathrm{sec})$ was presented immediately upon termination of the CS.

Acclimation. Acclimation to the experimental enclosure was conducted on Days 1 and 2 during daily 60-min sessions as was done in Experiments 1 and 2A.

Conditioning. Conditioning was conducted on Days 3-14 with the lick tubes removed. During each 60-min daily training session, both Corr groups received six $\mathrm{AX}-\mathrm{US}$ and six $\mathrm{BX}$-alone trials, whereas the Uncorr groups received three $\mathrm{AX}$-US, three AX-alone, three $\mathrm{BX}-\mathrm{US}$, and three $\mathrm{BX}$-alone trials. Group Cont-L received one $\mathrm{X}$-alone, six $\mathrm{A}-\mathrm{US}$, and six B-alone trials per session. The rationale for Group Cont-L was to assess baseline lick suppression to the intense (loud) X devoid of any X-US association and after giving sufficient exposures for habituation to eliminate unconditioned responding to $\mathrm{X}$. For all groups, trial types were pseudorandomly intermingled. All CSs were $10 \mathrm{sec}$ in duration. The mean ITI between events was $5 \mathrm{~min}$ (range $=3-7 \mathrm{~min}$ ).

Reacclimation. Reacclimation to the apparatus was conducted on Days 15-17 during daily 60-min sessions in the same manner as in the previous experiments.

Testing. On Day 18, all the subjects were tested for lick suppression in response to Stimulus $\mathrm{X}$. Testing was conducted as in the other experiments.

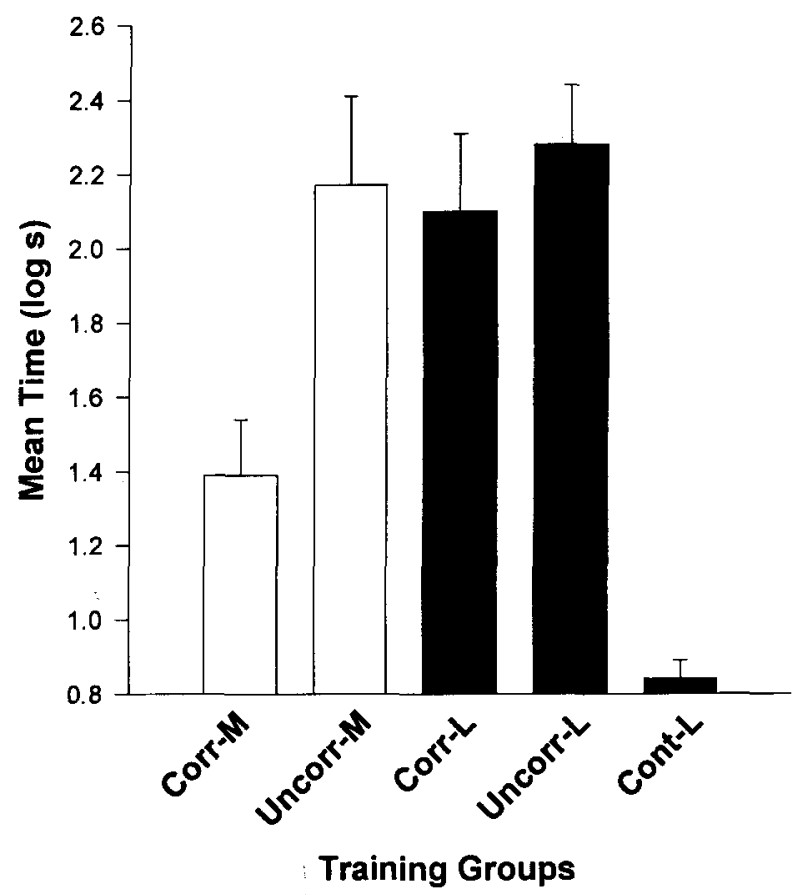

Figure 4. Experiment 3. Mean latencies to complete 5 cumulative seconds of drinking in the presence of Stimulus $X$. Groups Corr-M and Uncorr-M were trained and tested with stimuli of moderate intensity, whereas Groups Corr-L, Uncorr-L, and Cont-L were trained and tested with stimuli of high intensity. Although target $\mathrm{Cs} X$ was always reinforced $50 \%$ of the time, in condition Corr, $X$ was trained in the presence of other cues with a better correlation with the reinforcer than $X$ had, whereas in the Uncorr condition $X$ had the same predictive value as the other cues present during training of $X$. Error bars indicate the standard error of the mean. 
Two animals ( 1 from the Group Corr-M and 1 from the Group Uncorr-M) were excluded from the study prior to testing due to illness.

\section{Results and Discussion}

Figure 4 depicts the results of Experiment 3. Less conditioned suppression to $\mathrm{X}$ was observed in Group Corr- $\mathrm{M}$ than in Group Uncorr-M, whereas Groups Corr-L and Uncorr-L displayed similar and relatively high levels of suppression to X. Group Cont-L exhibited a low level of suppression to $X$, which indicated that the high level of suppression observed in Group Corr-L was not an unconditioned reaction to an intense click train (i.e., CS X). Thus, in Experiment 3, it was demonstrated that the relative stimulus validity effect is attenuated when the target CS is of high inherent biological significance. The following analyses support these conclusions.

A one-way ANOVA with group as the factor found no differences in time to complete the first 5 cumulative seconds of licking on the test day (i.e., prior to the presentation of any test stimulus) $[F(4,53)=2.05]$, which is indicative of similar baseline behavior across groups.

A similar ANOVA conducted on times to drink for 5 cumulative seconds in the presence of $\mathrm{X}$ revealed differences between groups $[F(4,53)=12.94]$. A second statistical analysis was then performed that excluded Group Cont-L in order to take advantage of the factorial arrangement of the four remaining groups. A $2 \times 2$ ANOVA with intensity (loud vs. moderate) and contingency (correlated vs. uncorrelated) as factors revealed main effects of intensity $[F(1,42)=4.53]$ and contingency $[F(1,42)=6.11]$, but the intensity $\times$ contingency interaction was less than statistically significant $[F(1,42)=$ $2.39, p=.13$ ], which was surprising given the appearance of Figure 4. Inspection of the data suggested that the lack of a statistically significant interaction was due to large within-group variance arising from the counterbalanced use of two different types of physical experimental enclosures ( $R$ and $V$ ). Consequently, we performed a $2 \times 2 \times 2$ ANOVA with intensity, contingency, and enclosure as factors. This revealed a main effect of intensity $[F(1,38)=6.51]$, contingency $[F(1,38)=$ $10.47]$, and enclosure $[F(1,38)=31.46]$, and, importantly, an intensity $\times$ contingency interaction $[F(1,38)=$ 4.12]. None of the other interactions were significant. Planned comparisons revealed that conditioned suppression to $\mathrm{X}$ was lower for the high correlation condition than for the low correlation condition $[F \mathrm{~s}(1,42)=7.73$ and 0.45 , respectively], but only when using CSs of moderate intensities.

The present results suggest that the relative stimulus validity effect was attenuated when the CSs were of high biological significance. This suggests that CSs of high biological significance are protected against cue competition not only in overshadowing preparations, as we saw in Experiment 2, but also in relative stimulus validity preparations. Moreover, this finding is consistent with the prior finding of Miller and Matute (1996) that CSs of high biological significance are protected against blocking.

\section{EXPERIMENT 4 \\ Degraded Contingency Treatment With Cues of Inherent Biological Significance}

The degraded contingency effect in animals was first reported by Rescorla (e.g., 1968), who showed that good contiguity between CSs and USs was not sufficient for stimulus control over conditioned responding. By adding unsignaled USs during CS-US training, he showed that responding to the CS was decreased, relative to control groups that had received the same number of CS-US pairings during training, in the absence of unsignaled USs. Since Rescorla's initial finding, the degraded contingency effect has been replicated by numerous researchers (e.g., Gamzu \& Williams, 1973; Jenkins, Barnes, \& Barrera, 1981). In Experiment 4, we sought to determine the extent to which the degraded contingency effect could be disrupted by the use of a CS with high inherent biological significance in contrast to previous studies of the degraded contingency effect, which all used CSs of seemingly low inherent biological significance.

\section{Method}

\section{Subjects}

The subjects were 30 male and 30 female Sprague-Dawley descended rats obtained from our own breeding colony. Body-weight ranges were $330-470 \mathrm{~g}$ for males and $240-330 \mathrm{~g}$ for females. The subjects were randomly assigned to one of five groups $(\mathrm{C}-\mathrm{L}$, DegradedC-L, C-M, DegradedC-M, Cont-L, $n \mathrm{~s}=12$ ), counterbalanced for sex. $C$ and DegradedC indicate the contingent and degraded contingency conditions, respectively; $\mathrm{L}$ and $\mathrm{M}$ indicate the loud (i.e., high biological significance) and moderate intensity (i.e., low biological significance) conditions, respectively, and Cont indicates the group intended to control for unconditioned responding to the loud CS. Animal care and maintenance, as well as the apparatus, were the same as in Experiment 1. Enclosures $R$ and $V$ were counterbalanced within groups.

\section{Procedure}

The parameters and procedural details were the same as in Experiment $2 \mathrm{~A}$, except where otherwise stated. The CS was the white noise presented at $30 \mathrm{~dB}$ above background (i.e., of high biological significance) for Groups $\mathrm{C}-\mathrm{L}$, DegradedC-L, and Cont-L, and $8 \mathrm{~dB}$ above background (i.e., of low biological significance) for Groups C-M and DegradedC-M. The stimulus was $30 \mathrm{sec}$ in duration, and the US was a $0.5-\mathrm{sec}, 1-\mathrm{mA}$ footshock. When signaled by the CS, the US coterminated with it. Longer CSs, as compared with those in the other experiments, and cotermination of the CS and US in this series were used in this study because prior research (Kasprow, Schachtman, \& Miller, 1987) had found that these parameters provided a strong degraded contingency effect.

Acclimation. Acclimation to the experimental enclosure was conducted on Days 1 and 2 during daily 45-min sessions. Acclimation was conducted as in Experiments 1,2A, and 3, except for the shorter sessions.

Conditioning. Conditioning was conducted on Days 3-8 with the lick tubes removed. During each daily 45-min training session Groups $\mathrm{C}-\mathrm{L}$ and $\mathrm{C}-\mathrm{M}$ experienced three $\mathrm{CS}-\mathrm{US}$ trials, pseudorandomly interspersed with three CS-alone trials (i.e., the CS was re- 


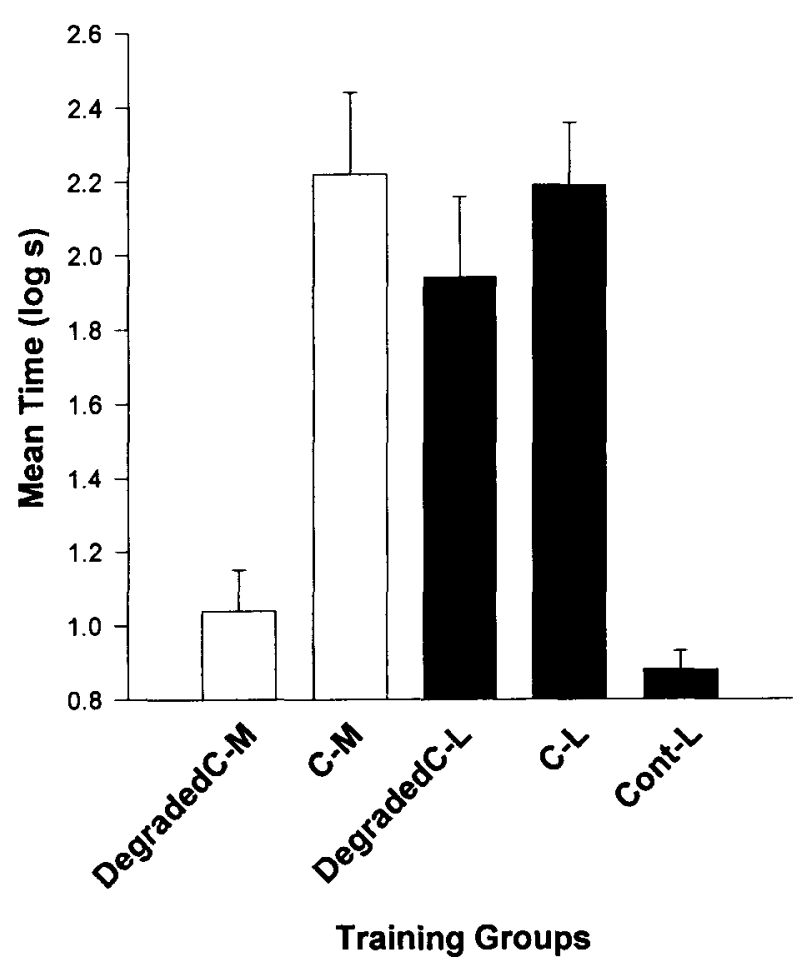

Figure 5. Experiment 4. Mean latencies to complete 5 cumulative seconds of drinking in the presence of the CS. Groups Degraded $C-M$ and $C-M$ were trained and tested with a $C S$ of moderate intensity, whereas Groups DegradedC $-\mathrm{L}, \mathrm{C}-\mathrm{L}$, and Cont-L were trained and tested with a $\mathrm{CS}$ of high intensity. During training, large numbers of unsignaled reinforcers were delivered only to the subjects in the degraded condition. Error bars indicate the standard error of the mean.

inforced on $50 \%$ of the trials), whereas Groups DegradedC- $\mathrm{L}$ and DegradedC-M experienced the same daily pattern of three CS-US trials and three CS-alone trials, but these trials were pseudorandomly interspersed with 42 daily unsignaled USs (footshocks). None of these 42 unsignaled USs occurred within $25 \mathrm{sec}$ of a CS-US pairing. Group Cont $-\mathrm{L}$ received six nonreinforced CS presentations pseudorandomly interspersed with 42 unsignaled footshocks during each daily session. The same pseudorandom sequence of trials was used for Groups DegradedC-L, DegradedC-M, and Cont-L. The average inter-CS interval was $7 \mathrm{~min}$ (range $=5-9 \mathrm{~min}$ ).

Reacclimation. On Days 9-13, the water-filled lick tubes were reinserted, and daily 45 -min reacclimation sessions were conducted. More reacclimation sessions were required because the unsignaled footshocks produced a high level of lick suppression to background cues that had to be extinguished before testing was possible.

Testing. On Day 14, all subjects were tested for lick suppression in response to the $\mathrm{CS}$. The test was conducted as in the prior experiments.

\section{Results and Discussion}

Figure 5 depicts the results of Experiment 4 . Less conditioned suppression to the CS was observed in Group DegradedC-M than in Group C-M, whereas Groups DegradedC- $\mathrm{L}$ and $\mathrm{C}-\mathrm{L}$ displayed similar and high levels of suppression to the CS. Group Cont-L exhibited a low level of suppression to the CS, which indicated that the high level of suppression to the CS observed in Group DegradedC-L was not an unconditioned reaction to the intense white noise CS. Thus, Experiment 4 demonstrated that a CS of high inherent biological significance was not as susceptible to the degraded contingency effect as was a CS of low inherent biological significance. The following analyses support these conclusions.

A one-way ANOVA with group as the factor conducted on times to complete the first 5 cumulative seconds of licking on the test day (i.e., prior to the presentation of any test stimulus) found no differences between groups $[F(4,55)=1.83]$, indicating similar baseline drinking behavior across groups.

A one-way ANOVA conducted on time to drink for 5 cumulative seconds in the presence of the test CS revealed a difference between groups $[F(4,55)=15.06]$. A second statistical analysis was performed, which excluded Group Cont-L, in order to take advantage of the factorial arrangement of the four remaining groups. A 2 $\times 2$ ANOVA with intensity (loud vs. moderate) and contingency (contingent vs. degraded contingency) as factors revealed main effects of intensity $[F(1,44)=5.57]$ and contingency $[F(1,44)=14.88]$ and an intensity $\times$ contingency interaction $[F(1,44)=6.44]$. Planned comparisons determined that conditioned suppression to the CS was lower in Group DegradedC-M than in Group C-M $[F(1,44)=20.45]$, but suppression was similar and high in Groups DegradedC-L and C-L $[F(1,44)=0.87]$. Thus, the degraded contingency effect was alleviated by the use of a CS with high inherent biological significance. Notably, the present attenuation of the degraded contingency effect with a CS of high biological significance cannot be attributed to unconditioned fear of an intense noise, as attested to by the low level of suppression observed in Group Cont-L. However, because of the contingency that existed between $\mathrm{X}$ and the US, the low level of suppression observed in Group Cont-L might reflect conditioned (differential) inhibition to the intense CS, rather than merely an absence of unconditioned fear. As mentioned previously, our data do not speak to this possibility. But the fact that we observed a low level of responding by the animals in Experiment 1 that received eight nonreinforced presentations of the same intense stimulus as opposed to the 36 presentations in the present experiment suggests that the attenuated amount of suppression seen here is likely the result of habituation.

\section{GENERAL DISCUSSION}

The present series of experiments demonstrates that Pavlovian cue competition phenomena are attenuated when CSs of high biological significance are used. First, we confirmed that our high intensity auditory stimuli elicited robust unconditioned responding (Experiment 1), which showed them to be of high biological significance by our definition. Then we demonstrated that overshadowing was attenuated by using CSs of either high inherent (Experiment 2A) or acquired (Experiment 2B) biolog- 
ical significance. Finally, we extended our findings with respect to inherent biological significance to the phenomena of relative stimulus validity (Experiment 3 ) and the degraded contingency effect (Experiment 4). The present results, in conjunction with Denniston et al.'s (1996) and Miller and Matute's (1996) findings that forward and backward blocking are attenuated when cues of high inherent and acquired biological significance are used, suggest that the attenuation of cue competition observed when the cues are of high biological significance occurs across most, if not all, forms of cue competition. This conclusion is also congruent with Mackintosh's (1976) finding that cross-modality overshadowing is disrupted when an intense tone is used as the target CS and a light is used as the overshadowing CS, and further demonstrates that his effect can be obtained even when controls for unconditioned responding to the target $\mathrm{CS}$ are included. Incidentally, consistent with the Rescorla-Wagner (1972) model and most other recent models of associative learning and contrary to Hull (1951) and Kamin (1965), CS intensity had little effect on the presumably asymptotic performance achieved in our studies by control subjects (see Figures 2, 4, and 5). That is, there was little difference in performance between control subjects that received high, as opposed to moderate, intensity CSs.

Despite the concordance of empirical observations, the mechanism by which biological significance acts to attenuate cue competition is still unclear. That is, an underlying model is needed to flesh out the hypothesis. Moreover, one might view what we have described as biological significance as not being very different from what others have called attention or cue salience (see, e.g., Broadbent, 1958; Mackintosh, 1975). Surely, the present concept of biological significance suggests processes that would be expected to command a high degree of attention. Indeed, these two hypothetical variables may ultimately prove to be identical. However, we hesitate at this time to simply equate biological significance with attention because this would blind us to potential differences between the two concepts.

The procedures and experimental designs used in the present research did not allow us to determine whether the absence of cue competition observed with stimuli possessing inherent or acquired biological significance reflects complete protection against cue competition starting with the early compound training trials or whether cue competition waned over the training trials. Both overshadowing (Bellingham \& Gillette, 1981) and blocking (Azorlosa \& Cicala, 1988) are known to wane with increasing numbers of compound training trials. If this waning of overshadowing and blocking stimuli reflects an asymptotic state and cues that are biologically significant at the start of the compound trials of cue competition treatment reach an asymptotic associative value more rapidly than cues of low biological significance, in Experiments $2 \mathrm{~A}$ and $2 \mathrm{~B}$ we might possibly have observed overshadowing with biologically significant cues if we had given fewer compound training trials. Thus, there is empirical reason to at least entertain the possibility that fewer compound trials than we used in Experiments $2 \mathrm{~A}$ and $2 \mathrm{~B}$ might have yielded cue competition in the high biological significance condition, as well as the low biological significance condition. Nevertheless, with the present number of training trials in Experiments $2 \mathrm{~A}$ and $2 \mathrm{~B}$, biologically significant stimuli were protected against overshadowing.

To our knowledge there is no reported data indicating whether large numbers of training trials also weaken the relative validity effect or the degraded contingency effect. However, the relative validity and degraded contingency effects are predicted by most contemporary learning theories (e.g., Rescorla \& Wagner, 1972) to develop as asymptotic behavior is approached and not to be as evident during early parts of training. Is it possible that the results of Experiments 3 and 4 can be accounted for by this prediction (i.e., might the cues of low biological significance have been closer to asymptote at test than were the cues of high biological significance)? Two factors argue against this possibility. First, we used parameters that in unpublished preliminary studies using cues of moderate auditory intensity resulted in asymptotic behavior for these two effects (i.e., 144 training trials of relative validity treatment in Experiment 3, and $36 \mathrm{CS}$ plus 252 unsignaled US presentations during degraded contingency treatment in Experiment 4). Second, contemporary learning theories all predict that the rate of acquisition will increase with the salience of the cues being trained. Increasing intensity presumably increases salience. Thus, these theories anticipate that groups trained with the loud CSs should have been closer to asymptote than the groups trained with the moderate intensity CSs, given the same number of training trials, and consequently should have been more apt to exhibit the relative validity and degraded contingency effects. Clearly this is contrary to our observations. Hence, even if training was not asymptotic, these learning theories are not able to account for the present findings of Experiments 3 and 4 based on training being subasymptotic. Indeed, they predict a bias against the effects that we observed.

Contemporary theories of learning, such as those of Mackintosh (1975), Pearce (1987), Pearce and Hall (1980), and Rescorla and Wagner (1972), predict that no cue competition will occur on the first compound trial of overshadowing, and Mackintosh (1975) and Pearce and Hall (1980) make a similar prediction for the first compound trial (with the target CS) in the relative validity and blocking procedures. Thus, these models can account for the protection from cue competition that is afforded by what we call inherent biological significance by assuming that intense CSs (i.e., high inherent biological significance) have high values of associability, which thereby allows them to acquire more associative strength on the first compound trial of a cue competition preparation. More problematic for this type of account is Experiment 2B, in which the target CS that was protected against overshadowing was not of high intensity. However, some of the 
aforementioned models allow the associability of CSs to change (Mackintosh, 1975; Pearce \& Hall, 1980), whereas others do not (Pearce, 1987; Rescorla \& Wagner, 1972). Models that assume that a CS's associability is constant cannot account for the observations in Experiment 2B, which demonstrated that acquired biological significance also provides protection against overshadowing. Among models that allow a CS's associability to change, Mackintosh assumed that consistent pairings of a CS with a US (saccharin in this case) increase the CS's associability, which can account for the results of Experiment 2B on the basis of greater acquisition on the first $\mathrm{AX}$-shock trial. In contrast, Pearce and Hall assumed that consistent pairings of a CS with a US decrease the CS's associability, which leads to the contrary prediction for the first compound trial. But according to Pearce and Hall, the surprise value of the shift from saccharin to shock would be expected to increase associability on subsequent compound trials; hence, Pearce and Hall (as well as Mackintosh) can account for all of the present results. However, neither Mackintosh's model nor Pearce and Hall's model correctly anticipate the role of biological significance in determining the conditions under which backward blocking (i.e., AX-US trials prior to A-US trials) will occur (Denniston et al., 1996; Miller \& Matute, 1996).

Importantly, we have identified two manipulations (i.e., cue intensity and conditioning) for making a CS biologically significant, thereby demonstrating that biological significance is not merely a synonym for a single manipulation. Perhaps the common feature of inherent and acquired biologically significant CSs is that both types of cues already convey information that is directly relevant to the homeostatic status of the subject, and therefore are given high priority in processing. A cue is presumably encoded (and retrieved) on the basis of its multiple attributes, not only on the basis of its perceptual features (e.g., color, shape, intensity, etc.), but also on its affective attributes (e.g., pleasant, unpleasant, biologically significant, etc.). Surprisingly, this is a well-established notion in the human literature (for reviews, see Baeyens, Eelen, \& van den Bergh, 1990; Blaney, 1986; Bower, 1992, as well as some of the classical conditioning studies by Martin \& Levey-e.g., Levey \& Martin, 1975), but not in the nonhuman literature.

Wagner and Brandon's (1989) AESOP model encompasses a construct that may be close to what we mean by "biological significance." AESOP postulates that the associative links of a given stimulus are encoded with respect to two distinctive memory representations, one being perceptual (sensory) and the other being emotive. Roughly speaking, AESOP assumes that during CS-US pairings, sensory-sensory, sensory-emotive, and emotive-emotive associations will be formed, with the observed conditioned response reflecting the summation of these different associations. In some sense, AESOP's emotive attribute of stimuli resembles our concept of biological significance. But AESOP does not attribute any sort of protection against cue competition to emotive value (but see Baeyens et al., 1990, for an argument that acquired affective value cannot be decreased).

The foregoing speculation notwithstanding, we are not at this point prepared to propose a principled theoretical framework that can account for the finding that cues with high biological significance are protected against cue competition. Before trying to incorporate the concept of biological significance into a broader theoretical framework, it would probably be prudent to further examine the impact of biologically significant stimuli in other Pavlovian preparations (e.g., Gunther et al., 1997).

One could argue that we should temper our conclusion that cues of high biological significance are protected against cue competition when we consider conditioned taste aversion. One might expect that all flavors would be cues of inherently high biological significance to animals, and, hence, would be relatively immune to cue competition. Nevertheless, there are several reports of blocking and overshadowing of flavors (e.g., Bonardi, Honey, \& Hall, 1990; Revusky, 1971). However, those experiments did not study parametric manipulations of the concentration of the target flavor to see whether blocking and overshadowing decrease with increasing concentration of the target flavor as is seen with increasing intensity in other stimulus dimensions (auditory intensity in our case). Additionally, when associated with a weak stimulus such as a mild odor, flavor has been repeatedly shown to potentiate, rather than to overshadow, the association between the odor and the US (the so-called taste-potentiated odor aversion effect, see Durlach \& Rescorla, 1980; Rusiniak, Hankins, Garcia, \& Brett, 1979). Without entering into a detailed discussion concerning the mechanisms that might explain taste potentiation, we note that taste-potentiated odor aversion is a possible example of biologically significant stimuli being immune to cue competition. Therefore, we are cautious about objections based on the view that the conditioned taste aversion literature demonstrates that high biological significance does not protect a stimulus from cue competition (see Fouquet, Oberling, \& Sandner, 2000, for a recent reanalysis of the problem of biologically significant CSs within conditioned taste aversion).

There is one phenomenon that may pose a challenge to the hypothesis that biologically significant cues are protected against cue competition. This is the overexpectation effect, which has been most convincingly demonstrated by Lattal and Nakajima (1998). The overexpectation effect consists of a pretrained target $\mathrm{CS}$ (A) losing responseeliciting potential as a result of being reinforced in compound with another pretrained CS (i.e., after $A \rightarrow U S$ and $B \rightarrow U S$ trials, $A B \rightarrow U S$ trials decrease responding to $A$ relative to the absence of $A B \rightarrow U S$ trials). If one views $B$ as competing with $A$ for behavior control, the observed decrease of responding to $\mathrm{A}$, which after initial training did elicit conditioned responding, appears problematic for our hypothesis. However, the overexpectation effect differs from other forms of cue competition. In the overexpectation procedure, there is presumably a shift in the 
focal training context of CS A (i.e., from the background cues alone to CS B); whereas in the other forms of cue competition, there is no shift in the context of the training CS (it is consistently the competing CSs). Future research will be necessary to determine the seriousness of this challenge.

The present experiments demonstrate that cues that control vigorous responding are relatively immune to most cue competition effects. This protection against cue competition can be either an inherent quality (e.g., Experiments $2 \mathrm{~A}, 3$, and 4 ) or an acquired quality (e.g., Experiment $2 \mathrm{~B}$ ) of the CS. We here have used the term biological significance to provide a unified variable for these qualities. One might ask if biological significance is perfectly reflected in the potential of a cue to elicit vigorous responding. Other research in our laboratory (Blaisdell et al., 2000) has been conducted to investigate this issue by examining whether protection against cue competition survived experimental extinction, which degraded conditioned responding to the target CS. Specifically, Blaisdell et al. asked whether protection from cue competition decreases if the acquired response-eliciting potential of a CS is reduced through extinction prior to the cue competition treatment. They found that massive extinction treatment did reduce protection from cue competition, but that a moderate amount of extinction treatment, although sufficient to eliminate conditioned responding, left intact protection from cue competition. Thus, elimination of what we here have called the biological significance of a CS appears to require more extinction trials than are required to eliminate conditioned responding to the CS. Hence, the potential of a CS to elicit responding appears to be a good but not perfect indicator of the CS's immunity to cue competition. Blaisdell et al. also found that CSs are protected against cue competition if they are biologically significant at the time of testing; that is, they need not have been biologically significant at the time of cue competition treatment in order to receive this protection. They demonstrated this by pairing a CS with an appetitive US following overshadowing treatment with an aversive US. These pairings of the CS with an appetitive US actually enhanced responding to the CS appropriate to the aversive US.

In addition to the aforementioned phenomena, Denniston et al. (1996) and Miller and Matute (1996) demonstrated that the concept of biological significance can account for the difficulty in obtaining a backward blocking effect (AX-US, followed by A-US), in contrast to the ease of obtaining a forward blocking effect (A-US, followed by $\mathrm{AX}-\mathrm{US}$ ). Thus, biological significance appears to provide a unified account of several diverse phenomena. Currently, there does not seem to be any alternative to biological significance as a variable that fully captures the quality affording a CS protection from cue competition. Given the pervasiveness of the protection against cue competition afforded by biological significance that was demonstrated in the present experi- ments, it seems likely that future models of associative learning and behavior will have to incorporate this variable or at least one like it.

\section{REFERENCES}

Ayres, J. J. B., Bombace, J. C., Shurtleff, D., \& Vigorito, M. (1985). Conditioned suppression tests of the context-blocking hypothesis: Testing in the absence of the preconditioning context. Journal of Experimental Psychology: Animal Behavior Processes, 11, 1-14.

Azorlosa, J. L., \& Cicala, G. A. (1988). Increased conditioning in rats to a blocked CS after the first compound trial. Bulletin of the Psychonomic Society, 26, 254-257.

Baeyens, F., Eelen, P., \& van den Bergh, O. (1990). Contingency awareness in evaluative conditioning: A case for unaware affectiveevaluative learning. Cognition \& Emotion, 4, 3-18.

Bellingham, W. P., \& GilleTte, K. (1981). Attenuation of overshadowing as a function of nondifferential compound conditioning trials. Bulletin of the Psychonomic Society, 18, 218-220.

BERNARD, C. (1856). Leçons de physiologie expérimentale appliquée à la médecine faites au Collège de France. Paris: Baillière.

Blaisdell, A. P., Denniston, J. C., Savastano, H. I., \& Miller, R. R. (2000). Counterconditioning of an overshadowed cue attenuates overshadowing of aversive associations. Journal of Experimental Psychology: Animal Behavior Processes, 26, 74-86.

Blaney, P. H. (1986). Affect and memory: A review. Psychological Bulletin, 99, 229-246.

Bonardi, C., Honey, R. C., \& Hall, G. (1990). Context specificity of conditioning in flavor-aversion learning: Extinction and blocking tests. Animal Learning \& Behavior, 18, 229-237.

Bouton, M. E. (1993). Context, time, and memory retrieval in the interference paradigms of Pavlovian learning. Psychological Bulletin, 114, 80-99.

Bower, G. H. (1992). How might emotions affect learning? In S. A. Christianson (Ed.), The handbook of emotion and memory: Research and theory (pp. 3-32). Hillsdale, NJ: Erlbaum.

Broadbent, D. E. (1958). Perception and communication. London: Pergamon.

CANNON, W. B. (1929). Organization for physiological homeostasis. Physiological Review, 9, 399-431.

Chapman, G. B. (1991). Trial order affects cue interaction in contingency judgment. Journal of Experimental Psychology: Learning, Memory, \& Cognition, 17, 837-854.

Denniston, J. C., Miller, R. R., \& Matute, H. (1996). Biological significance as a determinant of cue competition. Psychological Science, 7, 325-331.

Durlach, P. J., \& Rescorla, R. A. (1980). Potentiation rather than overshadowing in flavor-aversion learning: An analysis in terms of within-compound associations. Journal of Experimental Psychology: Animal Behavior Processes, 6, 175-187.

FOREE, D. D., \& LoLORDO, V. M. (1973). Attention in the pigeon: The differential effect of food getting vs. shock avoidance procedures. Journal of Comparative and Physiological Psychology, 85, 98-102.

FOREE, D. D., \& LoLORDO, V. M. (1975). Stimulus-reinforcer interactions in the pigeon: The role of electric shock and the avoidance contingency. Journal of Experimental Psychology: Animal Behavior Processes, 1, 39-46.

Fouquet, N., Oberling, P., \& SANDner, G. (2000). Differential effect of free intake versus oral perfusion in conditioned taste aversion. Manuscript submitted for publication.

Gamzu, E., \& Williams, D. R. (1973). Associative factors underlying the pigeon's keypecking in autoshaping procedures. Journal of the Experimental Analysis of Behavior, 19, 225-232.

GARCIA, J. (1989). Food for Tolman: Cognition and cathexis in concert. In T. Archer \& L. G. Nilsson (Eds.), Aversion, avoidance and anxiety: Perspectives on aversively motivated behavior (pp. 45-86). Hillsdale, NJ: Erlbaum.

Garcia, J., \& Koelling, R. A. (1966). Relation of cue to consequence in avoidance learning. Psychonomic Science, 4, 123-124. 
Gunther, L. M., Miller, R. R., \& Matute, H. (1997). CSs and USs: What's the difference? Journal of Experimental Psychology: Animal Behavior Processes, 23, 15-30.

Hull, C. L. (1951). Essentials of behavior. New Haven: Yale University Press.

Jenkins, H. M., Barnes, R. A., \& Barrera, F. J. (1981). Why autoshaping depends on trial spacing. In C. M. Locurto, H. S. Terrace, \& J. Gibbon (Eds.), Autoshaping and conditioning theory (pp. 255284). New York: Academic Press.

KAMIN, L. J. (1965). Temporal and intensity characteristics of the conditioned stimulus. In W. F. Prokasy (Ed.), Classical conditioning (pp. 118-147). New York: Appleton-Century-Crofts.

KAMIN, L. J. (1968). "Attention-like" processes in classical conditioning. In M. R. Jones (Ed.), Miami symposium on the prediction of behavior: Aversive stimulation (pp. 9-31). Miami, FL: University of Miami Press.

Kasprow, W. J., Schachtman, T. R., \& Miller, R. R. (1987). The comparator hypothesis of conditioned response generation: Manifest conditioned excitation and inhibition as a function of relative excitatory strengths of CS and conditioning context at the time of testing. Journal of Experimental Psychology: Animal Behavior Processes, $13,395-406$.

KESSEN, W. (1953). Response strength and conditioned stimulus intensity. Journal of Experimental Psychology, 45, 82-86.

LatTal, K. M., \& NAKAJIMA, S. (1998). Overexpectation in appetitive Pavlovian and instrumental conditioning. Animal Learning \& Behavior, 26, 351-360.

LeveY, A. B., \& Martin, I. (1975). Classical conditioning of human "evaluative" responses. Behavior Research \& Therapy, 13, 221-226.

LoLoRdo, V. M., JACOBS, W. J., \& ForeE, D. D. (1982). Failure to block control by a relevant stimulus. Animal Learning \& Behavior, 10, 183-193.

MACKInTosh, N. J. (1975). A theory of attention: Variations in the associability of stimuli with reinforcement. Psychological Review, 82, 276-298.

Mackintosh, N. J. (1976). Overshadowing and stimulus intensity. Animal Learning \& Behavior, 4, 186-192.

Miller, R. R., Hallam, S. C., \& Grahame, N. J. (1990). Inflation of comparator stimuli following CS training. Animal Learning \& Behavior, 18, 434-443.

MilleR, R. R., \& MATUTE, H. (1996). Biological significance in forward and backward blocking: Resolution of a discrepancy between animal conditioning and human causal judgment. Journal of Experimental Psychology: General, 25, 370-386.

Mrosovsky, N. (1990). Rheostasis: The physiology of change. New York: Oxford University Press.

Pavlov, I. P. (1927). Conditioned reflexes (G. V. Anrep, Trans.). London: Oxford University Press.

Pearce, J. M. (1987). A model for stimulus generalization in Pavlovian conditioning. Psychological Review, 94, 61-73.

Pearce, J. M., \& Dickinson, A. (1975). Pavlovian counterconditioning: Changing the suppressive properties of shock by association with food. Journal of Experimental Psychology: Animal Behavior Processes, 1, 170-177.

Pearce, J. M., \& Hall, G. (1980). A model for Pavlovian conditioning: Variations in the effectiveness of conditioned but not unconditioned stimuli. Psychological Review, 87, 532-552.

RANDICH, A., \& Ross, R. T. (1984). Mechanisms of blocking by contextual stimuli. Learning \& Motivation, 15, 106-117.

Rescorla, R. A. (1968). Probability of shock in the presence and absence of CS in fear conditioning. Journal of Comparative \& Physiological Psychology, 67, 1-5.

ResCorla, R. A., \& WAGNER, A. R. (1972). A theory of Pavlovian conditioning: Variations in the effectiveness of reinforcement and nonreinforcement. In A. H. Black \& W. F. Prokasy (Eds.), Classical conditioning II: Current research and theory (pp. 64-99). New York: Appleton-Century-Crofts.

REVUSKY, S. H. (1971). The role of interference in association over a delay. In W. K. Honig \& P. H. R. James (Eds.), Animal memory (pp. 155-213). New York: Academic Press.

Rusiniak, K. W., Hankins, W. G., Garcia, J., \& Brett, L. P. (1979). Flavor-illness aversions: Potentiation of odor by taste in rats. Behavioral \& Neural Biology, 25, 1-17.

SCHWEITZER, L., \& GREEN, L. (1982). Reevaluation of things past: A test of the "retrospective hypothesis" using a CER procedure in rats. Pavlovian Journal of Biological Science, 17, 62-68.

SHANKS, D. R. (1985). Forward and backward blocking in human contingency judgment. Quarterly Journal of Experimental Psychology, 37A, 1-21.

STEvens, S. S. (1959). The psychophysics of sensory function. In W. A. Rosenblith (Ed.), Sensory communication (pp. 1-34). Cambridge, MA: MIT Press.

WAGNER, A. R., \& Brandon, S. E. (1989). Evolution of a structured connectionist model of Pavlovian conditioning (AESOP). In S. B. Klein \& R, R. Mowrer (Eds.), Contemporary learning theories: Pavlovian conditioning and the status of traditional learning theory (pp. 149-189). Hillsdale, NJ: Erlbaum.

Wagner, A. R., Logan, F. A., Haberlandt, K., \& Price, T. (1968). Stimulus selection in animal discrimination learning. Journal of Experimental Psychology, 76, 171-180.

WASSERMAN, E. A. (1974). Stimulus-reinforcer predictiveness and selective discrimination learning in pigeons. Journal of Experimental Psychology, 103, 284-297.

\section{NOTE}

1. The concept of biological significance should not be confused with that of biological relevance (otherwise known as "preparedness"), which refers to a predisposition toward association between two stimuli (Foree \& LoLordo, 1973, 1975; Garcia, 1989; Garcia \& Koelling, 1966; LoLordo, Jacobs, \& Foree, 1982)

(Manuscript received November 12, 1998; revision accepted for publication November 12, 1999.) 